\title{
Quasi-continuous variation of the first premolars in the Polish population of the badger Meles meles
}

\author{
Elwira SZUMA
}

\begin{abstract}
Szuma E. 1994. Quasi-continuous variation of the first premolars in the Polish population of the badger Meles meles. Acta theriol. 39: 201-208.

The presence-absence polymorphism and the size of $\mathrm{P}^{1}{ }_{1}$ were studied in the Polish population of the badger Meles meles (Linnaeus, 1758) $(n=79) . \mathrm{P}^{1}$ is more often absent than $\mathrm{P}_{1}$. The lengths of $\mathrm{P}_{1}^{1}$ range from $0.97 \mathrm{~mm}$ to $2.63 \mathrm{~mm}(\mathrm{~V}=16.3-22.3)$. A breach in the continuous variation of the size of the teeth between their absence and the minimum length of the crown that is $0.97 \mathrm{~mm}$ suggests that a threshold mechanism, related to size, operates at an early stage of $\mathrm{P}^{1}{ }_{1}$ ontogeny. Such a mechanism would allow the development of a tooth only if it had reached the threshold size at the critical stage of its ontogeny. The correlation between the presence or absence of $\mathrm{P}^{1} 1$ and the number of roots of $\mathrm{P}^{2}{ }_{2}$ confirms the existence of a gradient in shape and size within the morphogenetic field of cheek teeth. The frequent occurrence of $\mathrm{P}^{1}{ }_{1}$ in the Polish population of the badger $(73 \%)$ corresponds to the clinal variation of the presence-absence polymorphism of the first premolars in Eurasia.

Mammal Research Institute, Polish Academy of Sciences, 17-230 Białowieża, Poland

Key words: Meles meles, first premolars, quasi-continuous variation, threshold mechanism, Poland
\end{abstract}

\section{Introduction}

The presence-absence polymorphism of $\mathrm{P}^{1}{ }_{1}$ in the badger has been described many times before (Heptner et al. 1974, Spittler and Jansen 1985, Baryshnikov and Potapova 1990, Lüps 1990). A comparison of the frequency of occurrence of $\mathrm{P}^{1}{ }_{1}$ showed that $\mathrm{P}^{1}$ is more often absent than $\mathrm{P}_{1}$. It was also demonstrated that the length and width of $\mathrm{P}^{1} 1$ are characterized by a coefficient of variation fluctuating between 10.2 and 15.0 (Lüps 1990).

Presence or absence of $\mathrm{P}^{1}{ }_{1}$ indicate a distinct clinal variation (Baryshnikov and Potapova 1990, Lüps 1990). Heptner et al. (1974) note that the lowest frequency of $\mathrm{P}^{1}$ is characteristic of Far East populations of the badger. Moving from the east towards the west the frequency of the occurrence of $\mathrm{P}^{1}{ }_{1}$ gradually grows.

It has so far not been explained what mechanism is responsible for the presence-absence polymorphism and variation in size of $\mathrm{P}^{1}{ }_{1}$ in the badger. Thus, the aim of the present study is an attempt to find the answer to the question: what determines the presence or absence of $\mathrm{P}^{1}{ }_{1}$ in the badger's dentition, and when it is present, what determines its size? At the same time, the morphogenetical field 
theory was tested by examining the dependence of presence or absence of $\mathrm{P}^{1} 1$ upon the number of roots and the size of $\mathrm{P}^{2}{ }_{2}$. Furthermore, the paper includes the comparison of the frequency of occurrence of $\mathrm{P}^{1}{ }_{1}$ in the dentition of the Polish badger in comparison with the populations from the neighbouring countries.

\section{Material}

The research was conducted on 79 skulls of the badger Meles meles (Linnaeus, 1758), including 16 females, 24 males and 39 specimens of an unknown sex. In six specimens the whole mandible was missing, and two lacked a dentary bone. Fourty-one badger's skulls came from the collection of the Mammal Research Institute of the Polish Academy of Sciences in Białowieża, 12 from the Institute of the Systematics and Evolution of Animals of the Polish Academy of Sciences in Cracow, seven from the Research Station of the Polish Hunters' Association in Czempin, six from the Natural History Museum of Wrocław University, five from the Institute of Biology of Maria Curie-Skłodowska University in Lublin, three from the Institute of Biology of the Teachers Training College in Olsztyn, four from Dr A. Nowosad's private collection from Poznań and one from the private collection of Mr R. Miklaszewski from Torun. All the above listed specimens were found in Poland between 1930 and 1992.

\section{Methods}

$\mathrm{P}^{1}{ }_{1}$ were considered present $(+)$ when: (1) the teeth were embedded in their alveoli; (2) the teeth fell out but their alveoli remained, (3) the alveoli overgrown with a bony tissue were visible. $\mathrm{P}^{1} 1$ were considered absent $(0)$ when in the place where $\mathrm{P}^{1}$ should occur there was no trace that they had been there before.

Measurements of left and right $\mathrm{P}_{1}^{1}$ and $\mathrm{P}^{2}{ }_{2}$ were taken with the measuring microscope, type WILD, exact to $0.01 \mathrm{~mm}$. Because there was no statistically significant difference in the frequency of occurrence of $\mathrm{P}^{1}{ }_{1}$ in males and females, the observations and measurements were analyzed jointly.

The following measurements were made: the length of $\mathrm{P}^{1}$ and $\mathrm{P}_{1}\left(\mathrm{LP}^{1}\right.$ and $\left.L \mathrm{P}_{1}\right)$ : the greatest distance between the anteriormost and posteriormost points of the crown of $\mathrm{P}^{1}$ and $\mathrm{P}_{1}$; the length of alveolus of $\mathrm{P}^{1}$ and $\mathrm{P}_{1}\left(\mathrm{LAP}^{1}\right.$ and $\left.\mathrm{LAP}_{1}\right)$ : the greatest diameter of the alveolar rim of $\mathrm{P}^{1}$ and $\mathrm{P}_{1}$; the length of $\mathrm{P}^{2}$ and $\mathrm{P}_{2}\left(\mathrm{LP}^{2}\right.$ and $\left.\mathrm{LP}_{2}\right)$ : the greatest distance between the anteriormost and posteriormost points of the crown of $\mathrm{P}^{2}$. The statistical analysis was based on the average of three repetitions of each measurement.

In order to describe the variation in number of roots of $\mathrm{P}^{2}{ }_{2}$ three morphotypes were distinguished: A, B and C. The definitions of morphotypes are given in the legend for Fig. 3.

Duncan's new multiple range test was used to estimate the differences between the average measurements (Duncan 1955). The correlation coefficient of Pearson $(r)$ was also counted in order to estimate the asymmetry of $\mathrm{P}^{1}$. The relation between the presence (absence) of $\mathrm{P}^{1}{ }_{1}$ and the number of roots of $\mathrm{P}^{2}{ }_{2}$ and between the presence (absence) of $\mathrm{P}^{1}{ }_{1}$ and the length of $\mathrm{P}^{2}{ }_{2}$ crowns were estimated by counting the correlation of quality traits.

\section{Results}

Taking 298 possible examples of $\mathrm{P}^{1}{ }_{1}$ (left and right $\mathrm{P}^{1}$ plus left and right $\mathrm{P}_{1}$ ) in 219 instances $(73 \%) \mathrm{P}^{1} 1$ were present (Table 1 ). In the Polish population of the 
badger eight variants of dentition, considering the presence or absence of $\mathrm{P}^{1}$, were found (Fig. 1).

The coefficients of variation $(\mathrm{V})$ of $\mathrm{LP}^{1} 1$ and $\mathrm{LAP}^{1} 1$ are about three times greater than those for $\mathrm{LP}_{2}^{2}$ (Table 2). The distribution of variability of left and right $\mathrm{LP}^{1}$ and left and right $L P_{1}$ show the positive asymmetry. Measurements of $L P^{1}$ reach the highest frequency in the range from $1.15 \mathrm{~mm}$ to $1.90 \mathrm{~mm}$ (78\% of measurements) whereas the characteristic measurements of $\mathrm{LP}_{1}(78 \%)$ converge in the

Table 1. Frequency of occurrence of $\mathrm{P}^{1}{ }_{1}$ in the Polish population of the badger. $n \mathrm{p}$ - number of present $\mathrm{P}^{1}{ }_{1}, n \mathrm{a}-$ number of absent $\mathrm{P}^{1}{ }_{1}$.

\begin{tabular}{|c|c|c|c|c|c|c|c|c|c|c|c|c|}
\hline & \multicolumn{4}{|c|}{ Left } & \multicolumn{4}{|c|}{ Right } & \multicolumn{4}{|c|}{ Total } \\
\hline & $n \mathrm{p}$ & $\%$ & na & $\%$ & $n p$ & $\%$ & $n \mathrm{a}$ & $\%$ & $n p$ & $\%$ & $n \mathrm{a}$ & $\%$ \\
\hline $\mathrm{P}^{1}$ & 46 & 59 & 32 & 41 & 46 & 59 & 31 & 41 & 92 & 59 & 63 & 41 \\
\hline $\mathrm{P}_{1}$ & 64 & 89 & 8 & 11 & 63 & 90 & 7 & 10 & 127 & 89 & 15 & 11 \\
\hline
\end{tabular}

Table 2. Descriptive statistics for the $\mathrm{P}^{1}{ }_{1}$ measurements (mm), according to body side. $n$ - number of teeth, OR - observed range, $x$ - average, SD - standard deviation, $\mathrm{SE}$ - standard error mean, $\mathrm{V}$ - coefficient of variation.

\begin{tabular}{llcccccc}
\hline $\begin{array}{l}\text { Measu- } \\
\text { rement }\end{array}$ & $\begin{array}{l}\text { Body } \\
\text { side }\end{array}$ & $n$ & OR & $x$ & SD & SE & V \\
\hline LAP $^{1}$ & left & 37 & $1.12-2.60$ & 1.63 & 0.30 & 0.05 & 18.10 \\
LAP $^{1}$ & right & 40 & $1.21-2.27$ & 1.60 & 0.25 & 0.04 & 15.46 \\
$\mathrm{LAP}_{1}$ & left & 42 & $1.09-2.20$ & 1.72 & 0.26 & 0.04 & 15.38 \\
$\mathrm{LAP}_{1}$ & right & 42 & $1.10-2.41$ & 1.70 & 0.30 & 0.05 & 17.88 \\
$\mathrm{LP}^{1}$ & left & 17 & $1.15-2.55$ & 1.62 & 0.36 & 0.09 & 22.31 \\
$\mathrm{LP}^{1}$ & right & 20 & $0.97-2.17$ & 1.50 & 0.32 & 0.07 & 21.31 \\
$\mathrm{LP}_{1}$ & left & 22 & $1.31-2.37$ & 1.67 & 0.27 & 0.06 & 16.34 \\
$\mathrm{LP}_{1}$ & right & 32 & $1.23-2.63$ & 1.75 & 0.35 & 0.06 & 20.23 \\
$\mathrm{LP}^{2}$ & left & 41 & $3.94-5.37$ & 4.78 & 0.30 & 0.05 & 6.28 \\
$\mathrm{LP}^{2}$ & right & 45 & $4.07-5.55$ & 4.75 & 0.29 & 0.05 & 6.03 \\
$\mathrm{LP}_{2}$ & left & 60 & $4.39-5.82$ & 5.14 & 0.30 & 0.04 & 5.74 \\
$\mathrm{LP}_{2}$ & right & 59 & $4.39-5.67$ & 5.04 & 0.28 & 0.04 & 5.57 \\
\hline
\end{tabular}

classes from $1.30 \mathrm{~mm}$ to $2.05 \mathrm{~mm}$ (Fig. 2A, B). The distribution of variation of $\mathrm{LAP}^{1}$ and LAP 1 has a slight positive asymmetry. The characteristic measurements of LAP $^{1}$ comprise the class categories from $1.30 \mathrm{~mm}$ to $1.90 \mathrm{~mm}(80 \%)$ whereas $75 \%$ of measurements of $\mathrm{LAP}_{1}$ fall into the category from $1.30 \mathrm{mim}$ to $2.05 \mathrm{~mm}$ (Fig. 2C, D).

Correlations between $\mathrm{LP}^{1}$ and $\mathrm{LP}_{1}$ as well as between $\mathrm{LAP}^{1}$ and $\mathrm{LAP}_{1}$, for both left and right side of the body, turned out to be statistically insignificant $(p>0.1)$. 


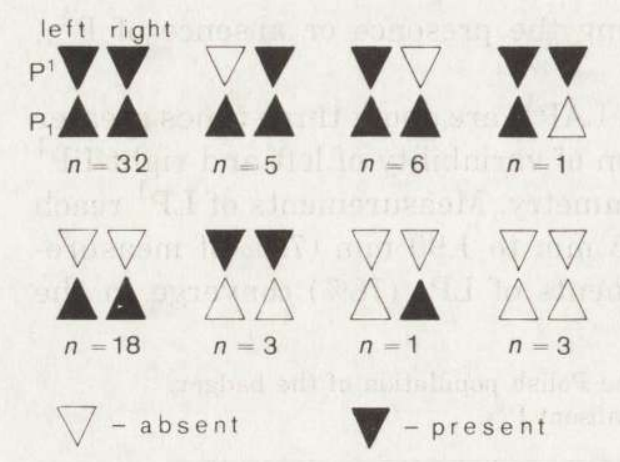

Fig. 1. Configurations of presence-absence of $\mathrm{P}^{1}$ found in 69 skulls of the badger from Poland.
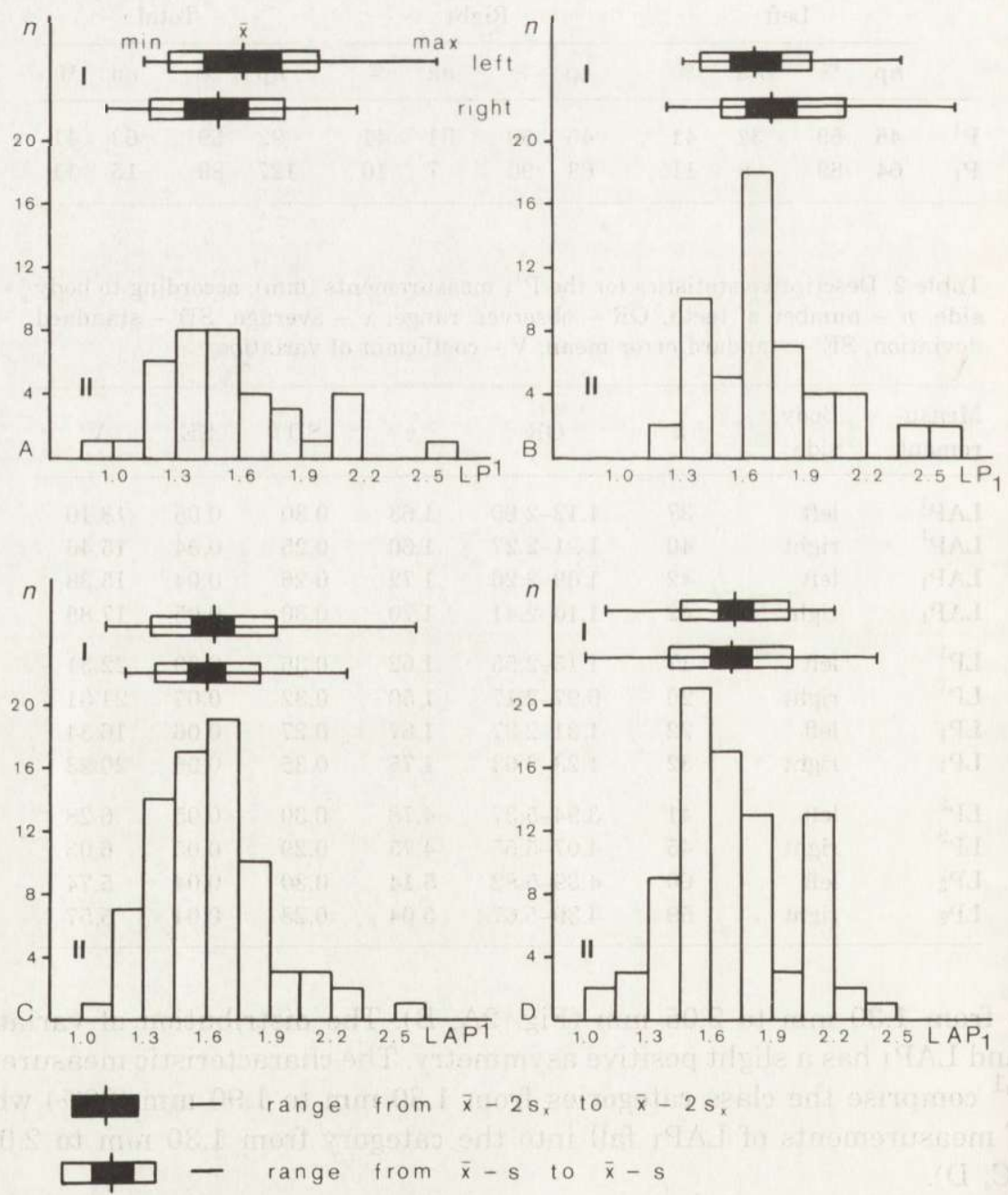

Fig 2. The range of variation (I) and the distribution of frequency (II) for: (A) left and right $\mathrm{LP}^{1}$, (B) left and right $\mathrm{LP}_{1},(\mathrm{C})$ left and right $\mathrm{LAP}^{1}$, (D) left and right $\mathrm{LAP}_{1}, n$ - the number of teeth; the borders of classes for $\mathrm{LP}^{1}, \mathrm{LP}_{1}, \mathrm{LAP}^{1}$ and $\mathrm{LAP}_{1}$ are given in $\mathrm{mm}$. 
Statistically significant differences in the length of left and right alveoli of $\mathrm{P}^{1}$ and $\mathrm{P}_{1}$, as well as left and right crowns of $\mathrm{P}^{1}$ and $\mathrm{P}_{1}$, were not found $(p>0.05$; Table 3 ). The correlation of the size of $\mathrm{P}^{1}{ }_{1}$ between left and right alveoli of $\mathrm{P}^{1}$, left and right alveoli of $\mathrm{P}_{1}$ as well as left and right $\mathrm{P}_{1}$ are statistically significant (Table 4 ).

Fig. 3. Variation of $\mathrm{P}^{2}$ and $\mathrm{P}_{2}$ concerning the number of roots in 79 skulls of the badger. $\mathrm{A}-\mathrm{a}$ tooth with one root: the lack of concavity on the top of the root or lack of bony septum at the bottom of the alvelous; B - a tooth with a partially divided root: in the outline of the root and along the root, one can see a channel or a hollow; the root divides into two parts at most up to the middle of its height; a bony septum is present down to the middle of the alveolus depth; C - a two-rooted tooth: it divides into two roots; the alveolus with a bony septum reaching more than a half of its depth. The numbers above the posts denote the number of $\mathrm{P}^{2}$ and $\mathrm{P}_{2}$ classified to each of the three morphotypes.
Table 3. Differences between the mean tooth measurements made, based on data from Table 2. - not significant, $+p<0.05$.

\begin{tabular}{lcccc}
\hline & \multicolumn{2}{c}{$\mathrm{LP}_{2}$} & & $\mathrm{LP}^{2}$ \\
\cline { 2 - 3 } & right & left & & right \\
\hline $\mathrm{LP}^{2}$ left & + & + & \\
$\mathrm{LP}^{2}$ right & + & + & \\
$\mathrm{LP}_{2}$ left & - & & \\
\hline
\end{tabular}

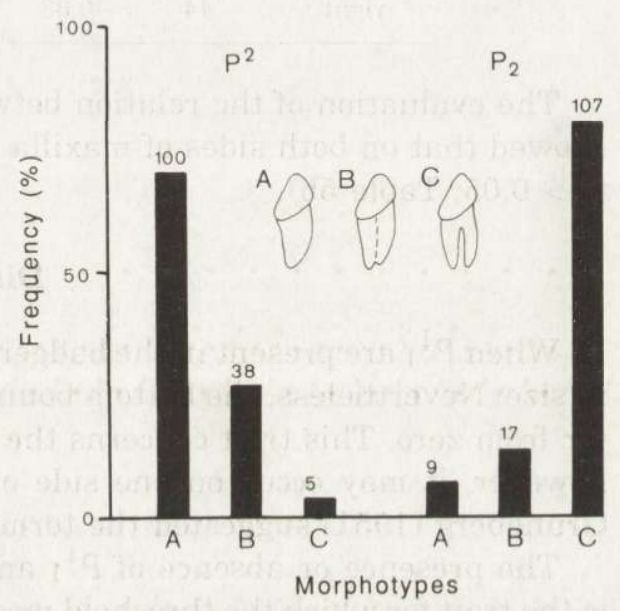

Table 4. Correlation coefficient of size of $\mathrm{P}^{1}{ }_{1}$ between left and right side for the crown and alveolus in the upper and lower jaw.

\begin{tabular}{cccccccc}
\hline & \multicolumn{3}{c}{ Alveolus } & & \multicolumn{3}{c}{ Crown } \\
\cline { 2 - 4 } \cline { 5 - 8 } & $n$ & $r$ & $\%$ & & $n$ & $r$ & $\%$ \\
\hline $\mathrm{P}^{1}$ & 30 & 0.56 & 31.3 & & 10 & 0.37 & 13.4 \\
& & $p<0.005$ & & & & $p>0.1$ & \\
$\mathrm{P}_{1}$ & 34 & 0.76 & 57.3 & & 18 & 0.91 & 83.0 \\
& & $p<0.001$ & & & & $p<0.001$ & \\
\hline
\end{tabular}

The statistically significant negative correlation $(p<0.001)$ between the frequency of occurrence of $\mathrm{P}^{1}$ and the number of roots of $\mathrm{P}^{2}$ was noted. The same relation in mandible appeared to be statistically insignificant $(p>0.1$; Table 5a). $\mathrm{P}_{1}$ was present in about $90 \%$ of specimens and the predominant morphotype in $\mathrm{P}_{2}$, as far as the number of roots is concerned, was a two-rooted tooth (morphotype C, 80\%; Fig. 3). 
Table 5. Correlation coefficient between: (a) number of roots in $\mathrm{P}^{2}{ }_{2}$ and presence of the adjacent $\mathrm{P}^{1}{ }_{1}$, (b) size of $\mathrm{P}^{2}{ }_{2}$ and presence of the adjacent $\mathrm{P}^{1}{ }_{1}, n$ - sample size, $r$ - correlations coefficient, $t$-statistical significance, $* p<0.01$.

\begin{tabular}{lcccccccc}
\hline \multirow{2}{*}{$\begin{array}{l}\text { Body } \\
\text { side }\end{array}$} & \multicolumn{3}{c}{ Maxilla } & & \multicolumn{3}{c}{ Mandible } \\
\cline { 2 - 4 } \cline { 5 - 7 } & $n$ & $r$ & $t$ & & $n$ & $r$ & $t$ \\
\hline $\begin{array}{c}\text { (a) left } \\
\text { right }\end{array}$ & 71 & -1.98 & $5.67^{*}$ & & 68 & -4.38 & 1.97 \\
(b) left & 72 & -2.00 & $5.62^{*}$ & & 65 & -4.59 & 1.83 \\
$\quad$ right & 40 & -0.29 & 1.96 & & 59 & 0.11 & 0.85 \\
& 44 & -0.33 & 2.42 & & 58 & 0.10 & 0.79 \\
\hline
\end{tabular}

The evaluation of the relation between the presence of $\mathrm{P}^{1}{ }_{1}$ and the size of $\mathrm{P}^{2}$ showed that on both sides of maxilla and mandible it is statistically insignificant $(p>0.05$; Table $5 \mathrm{~b})$.

\section{Discussion}

When $\mathrm{P}^{1}{ }_{1}$ are present in the badger's dentition they show a continuous variation in size. Nevertheless, the bottom boundary of the size of the teeth is always moved far from zero. This trait concerns the specimens of either sex to the same degree, however, it may occur on one side or on both sides. For this type of variation, Grüneberg (1951) suggested the term "quasi-continuous variation".

The presence or absence of $\mathrm{P}^{1} 1$ and the variability in size and shape of teeth is the trait for which the threshold mechanism is most probably responsible (Searle 1958). According to the threshold mechanism theory the germs of $\mathrm{P}^{1}{ }_{1}$ that at the critical stage reached the required threshold size, can continue further development, while the smaller structures undergo the atrophy. The action of thresholds consists in allowing or hindering the further development of the structures - in this case, tooth germs. Whether a tooth at the threshold stage will or will not reach the dimensions necessary for further development may be conditioned by both genetic or environmental factors (Grüneberg 1951, Searle 1958, Wolsan 1989). The genetical information accounts for the antethreshold morphological pattern as well as the threshold height and the duration of action in course of the ontogeny. The environmental factors can modify the final morphological pattern. Nevertheless, it seems that non-genetic factors cause only a slight shifting of the threshold level and threshold stage (Wolsan 1989).

The dentition of mammals may be morphologically varied along the mesial-distal axis, within three morphogenetical fields, which correspond to a group of incisors, canines, and a group of cheek teeth (Butler 1939). Each field includes a gradient of size and shape of the structures that constitute the field. The teeth that are most stable in size and shape form the centre of the field, while more variable teeth move towards its verges (Lombardi 1978). 
The studies on the badger in Switzerland $(n=40)$ indicate that the teeth that are most stable in size and shape are $\mathrm{I}_{2}^{1}, \mathrm{C}^{1}{ }_{1}, \mathrm{P}^{4}, \mathrm{M}_{1}$ (Lüps and Roper 1988).

$\mathrm{P}^{1}{ }_{1}$ is situated in the most peripheral position in the morphogenetical field of cheek teeth. Quite often $\mathrm{P}^{1}{ }_{1}$ does not erupt, which is characteristic of the badger, and when it is present it frequently falls out early in animal's life. The coefficient of variation of $\mathrm{LP}_{1}^{1}$ is about three times greater than those for $\mathrm{LP}_{2}^{2}$ (Table 2). $\mathrm{P}^{1}$ is more often absent than $\mathrm{P}_{1}$. Furthermore, on both sides of the maxilla the frequency of $\mathrm{P}^{1}$ tends to be lower and the number of roots of $\mathrm{P}^{2}$ gets smaller, whereas in the mandible, the two-rooted $\mathrm{P}_{2}$ is almost permanently accompanied by $\mathrm{P}_{1}$. It seems that the direction of changes taking place at the verge of the row of cheek teeth in maxilla is more progressive than the changes affecting $\mathrm{P}_{1}$ and $\mathrm{P}_{2}$. Lüps and Roper (1988) note that $\mathrm{P}^{1}$ undergoes a stronger reduction in size and it more often does not erupt than $\mathrm{P}_{1}$. Similar directions of reducing the size and losing peripheral teeth are known in other mammals, for example Vulpes vulpes (Ratcliffe 1970), Felis bengalensis (Glass and Todd 1977), Martes martes, $M$. foina (Wolsan et al. 1985). In accordance with the findings of the morphogenetical field theory (Butler 1939, Osborn 1978) and on the basis of my own data as well as those of Lüps and Roper (1988), one can assume that $\mathrm{P}^{1}{ }_{1}$ are the most variable teeth within the premolars just as in the whole badger's dentition.

Polymorphism of $\mathrm{P}_{1}^{1}$ occurs within the whole Eurasian range of the badger. In the specimens from the populations living farthest to the east $\mathrm{P}^{{ }_{1}}$ occur very rarely, for example in the badgers from Kazakhstan the percent of present $\mathrm{P}^{1}{ }_{1}$ approaches $2 \%$ (Heptner et al. 1974). In the badgers from central Asia the frequency of $\mathrm{P}^{1} 1$ reache $30 \%\left(n=23\right.$, Lüps 1990). In the Polish population of the species, $\mathrm{P}^{1}{ }_{1}$ are present in $73 \%(n=79)$. Lüps (1990) notes that the frequency of $\mathrm{P}^{1} 1$ for the badger from central Switzerland equals $71 \%(n=315)$, while for Denmark it is $70 \%(n$ $=100$ ). The tooth reached the highest frequency of occurrence in Romania (about $80 \%, n=47$ ). These data suggest that in the central Europe the frequency of occurrence of $\mathrm{P}^{1} 1$ is similar and ranges from $70 \%$ to $75 \%$.

Acknowledgements: I wish to thank Dr M. Wolsan for numerous, inestimable directions and critical remarks in the course of my research and writing of the paper. I also thank Prof $Z$. Pucek for critical reading of an earlier version of this paper. I want to thank the persons who rendered the specimens of the badger that were used in the research accessible to me: Dr A. Nadachowski, Mr G. Lipecki (Kraków), Prof Z. Pielowski (Czempiń), Dr T. Kokurewicz (Wrocław), Prof J. Kubik (Lublin), Dr J. Dynowski (Olsztyn), Dr A. Nowosad (Poznań), Mr R. Miklaszewski (Toruń).

\section{References}

Baryshnikov G. F. and Potapova O. R. 1990. Variability of the dental system in badgers (Meles, Carnivora) of the USSR. Zool. Ž. 69: 84-97. [In Russian with English summary]

Butler P. M. 1939. Studies of the mammalian dentition. Differentiation of the postcanine dentition. Proc. zool. Soc. Lond. 109: 1-36.

Duncan P. B. 1955. Multiple range and multiple F test. Biometrics 11: 1-42.

Glass G. E. and Todd N. B. 1977. Quasi-continuous variation of the second upper premolar in Felis bengalensis Kerr, 1792 and its significance for some fossil lynxes. Z. Säugetierk. 42: 36-44. 
Grüneberg H. 1951. Genetical studies on the skeleton of the mouse. IV. Quasi-continuous variations. J. Genet. 51: 95-114.

Heptner V. G., Naumov N. P., Jürgenson P. B., Sludski A. A., Cirkova A. F. and Bannikov A. G. 1974. Unterfamilie Melinae Burmeister 1850, Dachse. Gattung Meles Brisson 1762, Dachse. [In: Die Säugetiere der Sowietunion II. Seekühe und Raubtiere. V. G. Heptner and N. P. Naumov, eds]. VEB Gustav Fisher, Jena: 803-836.

Lombardi V. 1978. A factor analysis of morphogenetic fields in the human dentition. [In: Development, function and evolution of teeth. P. M. Butler and K. A. Joysey, eds]. Academic Press, London: 203-213.

Lüps P. 1990. Untersuchungen am P1 im Gebiss des europäischen Dachses (Meles meles). Z. Säugetierk. 55: 16-27.

Lüps P. and Roper T. J. 1988. Tooth size in the European badger (Meles meles) with special reference to sexual dimorphism, diet and intraspecific aggression. Acta theriol. 33: 21-33.

Osborn J. W. 1978. Morphogenetic gradients: fields versus clones. [In: Development, function and evolution of teeth. P. M. Butler and K. A. Joysey, eds]. Academic Press, London: 171-201.

Ratcliffe P. R. 1970. The occurrence of vestigial teeth in badger (Meles meles), roe deer (Capreolus capreolus) and fox (Vulpes vulpes) from the county of Argyll, Scotland. J. Zool., Lond. 162: 521-525.

Searle A. G. 1958. The genetics and evolution of threshold characters. Proc. Cent. Bicent. Congr. Singapore: $220-224$.

Spittler H. and Jensen B. 1985. Zur Reduktion des 1. Praemolaren beim Dachs (Meles meles L.). Z. Jagdwiss. 31: 42-46.

Wolsan M. 1989. Dental polymorphism in the genus Martes (Carnivora: Mustelidae) and its evolutionary significance. Acta theriol. 34: 545-593.

Wolsan M., Ruprecht A. L. and Buchalczyk T. 1985. Variation and asymmetry in the dentition of the pine and stone martens (Martes martes and M. foina) from Poland. Acta theriol. 30: 79-114.

Received 2 December 1993, accepted 22 April 1994. 